\title{
Co-infections of MERS-CoV with other respiratory viruses in Saudi Arabia
}

\author{
${ }^{* 1}$ Al-Quthami, K., ${ }^{2} \mathrm{Al}-$ Waneen, W. S., and ${ }^{3} \mathrm{Al}$ Johnyi, B. O. \\ ${ }^{1}$ Regional Laboratory, Makkah, Saudi Arabia \\ ${ }^{2}$ National Centre of Agricultural Technology, King Abdulaziz City for Science and Technology, Saudi Arabia \\ ${ }^{3}$ King Abdulaziz University, Saudi Arabia \\ *Correspondence to: khmrqu@hotmail.com
}

\begin{abstract}
:
Background: The Middle East Respiratory Syndrome (MERS) is a viral respiratory disease caused by a member of the coronaviruses called Middle East Respiratory Syndrome Coronavirus (MERS-CoV). The co-infections of MERS$\mathrm{CoV}$ with other respiratory viruses have been documented in rare cases in the scientific literature. This study was carried out to determine whether confection of MERS-CoV occurs with other respiratory viruses in Saudi Arabia.

Methods: Nasopharyngeal swabs samples of 57 MERS-CoV positive outpatients were collected using flocked swabs. Nucleic acid was extracted from each sample using commercial NucliSens easyMAG system. Amplification was performed by multiplex RT-PCR using Fast Track Diagnostics Respiratory Pathogen 33. Data were analyzed with SPSS software version 19 and comparison of variables was done with Fisher Exact test, with $p$ value <0.05 considered significant.

Results: Six of the total 57 MERS-COV patients (35 males, 22 females) were positive for co-infection of MERS CoV with other respiratory viruses, giving a prevalence rate of $10.5 \%$, with $14.5 \%(5 / 35)$ in males and $4.5 \%(1 / 22)$ in females $(\mathrm{OR}=3.500,95 \% \mathrm{CI}=0.3806-32.188, p=0.3889)$. The prevalence of co-infections was significantly higher among non-Saudis $(23.8 \%, 5 / 21)$ than Saudis $(2.8 \%, 1 / 36)(\mathrm{OR}=0.09143,95 \% \mathrm{CI}=0.009855-0.8485, p=0.0217)$, and among the age group $18-34$ years $(25 \%, 3 / 12)$ than other age groups $\left(X^{2}=3.649, p=0.1613\right)$. Human rhinovirus (HRV) was found in 2 of the $6(33.3 \%)$ patients with co-infection while the other viruses were found in each of the remaining 4 patients.

Conclusion: Our study confirms that MERS-CoV co-infects with other respiratory viruses in Saudi Arabia.
\end{abstract}

Keywords: MERS-CoV; URTI; Co-infection; Coronavirus

Received April 6, 2020; Revised May 30, 2020; Accepted May 31, 2020

Copyright 2020 AJCEM Open Access. This article is licensed and distributed under the terms of the Creative Commons Attrition 4.0 International License <a rel="license" href="http://creativecommons.org/licenses/by/4.0/", which permits unrestricted use, distribution and reproduction in any medium, provided credit is given to the original author(s) and the source.

\section{Co-infections de MERS-CoV avec d'autres virus respiratoires en Arabie saoudite}

\author{
${ }^{* 1}$ Al-Quthami, K., ${ }^{2}$ Al-Waneen, W. S., et ${ }^{3}$ Al Johnyi, B. O.
}

${ }^{1}$ Laboratoire régional, La Mecque, Arabie saoudite

${ }^{2}$ Centre national de technologie agricole, ville du roi Abdulaziz pour la science et la technologie, Arabie saoudite

${ }^{3}$ King Abdulaziz University, Arabie saoudite

*Correspondance à: khmrqu@hotmail.com

\section{Abstrait:}

Contexte: Le syndrome respiratoire du Moyen-Orient (MERS) est une maladie respiratoire virale causée par un membre des coronavirus appelé coronavirus du syndrome respiratoire du Moyen-Orient (MERS-CoV). Les coinfections de MERS-CoV avec d'autres virus respiratoires ont été documentées dans de rares cas dans la littérature scientifique. Cette étude a été réalisée pour déterminer si la confection du MERS-CoV se produit avec d'autres virus respiratoires en Arabie saoudite.

Méthodes: Des écouvillons nasopharyngés de 57 patients ambulatoires positifs au MERS-CoV ont été prélevés à 
I'aide d'écouvillons floqués. L'acide nucléique a été extrait de chaque échantillon en utilisant le système NucliSens easyMAG commercial. L'amplification a été réalisée par RT-PCR multiplex en utilisant Fast Track Diagnostics Respiratory Pathogen 33. Les données ont été analysées avec le logiciel SPSS version 19 et la comparaison des variables a été effectuée avec le test Fisher Exact, avec une valeur $p<0,05$ considérée comme significative.

Résultats: Six des 57 patients MERS-COV ( 35 hommes, 22 femmes) étaient positifs pour la co-infection de MERS CoV avec d'autres virus respiratoires, donnant un taux de prévalence de $10,5 \%$, avec $14,5 \%(5 / 35)$ chez les hommes et $4,5 \%(1 / 22)$ chez les femelles (OR 3.500, 95\% CI $0.3806-32.188, p=0.3889)$. La prévalence des co-infections était plus élevée chez les non-saoudiens $(23.8 \%, 5 / 21)$ que chez les saoudiens $(2.8 \%, 1 / 36)(\mathrm{OR}=0.09143,95 \%$ $\mathrm{CI}=0.009855-0.8485, p=0.0217)$ et parmi le groupe d'âge de 18 à 34 ans $(25 \%, 3 / 12)$ que dans les autres groupes d'âge $\left(X^{2}=3.649, p=0.1613\right)$. Le rhinovirus humain (VRC) a été trouvé chez 2 des $6(33,3 \%)$ patients co-infectés tandis que les autres virus ont été trouvés chez chacun des 4 patients restants.

Conclusion: Notre étude confirme que le MERS-CoV co-infecte avec d'autres virus respiratoires en Arabie Saoudite.

Mots-clés: MERS-CoV; URTI; Co-infection; Coronavirus

\section{Introduction:}

The Middle East Respiratory Syndrome is a viral respiratory disease caused by member of a coronavirus called Middle East Respiratory Syndrome Coronavirus (MERS-CoV). The virus was first discovered in Saudi Arabia in September 2012. The health officials carried out a retrospective investigation later and identified that the first known cases of MERS occurred in Jordan in April 2012 (1). After its first identification in Saudi Arabia, MERS rapidly spread to other countries, resulting in health crises at the international level. As of June 2015, MERS-CoV had spread to more than 20 countries $(2,3)$. The morbidity and mortality caused by MERS-CoV were particularly alarming, with mortality rate approaching 60\% (4). By June 19, 2015, a total of 1035 confirmed cases of MERS-CoV were reported by the Ministry of Health in Saudi Arabia with 458 deaths (case fatality rate of $44 \%$ ).

The clinical spectrum of MERS-CoV disease ranges from asymptomatic or mild respiratory symptoms to severe acute respiratory disease and ultimately death. The typical symptoms of MERS include cough, shortness of breath and fever (5). Pneumonia is a common finding but is not always present. Others such as gastrointestinal symptoms like diarrhea have also been reported. About three to four out of every ten patients or rather $36 \%$ of patients reported with MERS have succumbed to the illness (6). In its severe form, MERS can cause respiratory failure that will warrant mechanical ventilation support in an intensive care unit. Severe disease occurs in older populations, immunosuppressed, and those with underlying chronic diseases such as diabetes, chronic lung disease and cancer (2).

The MERS-CoV virus is a zoonotic type transmitted from animals to humans. The studies on the origins of the virus are still inconclusive, but according to an analysis of the different genomes of the virus, it is believed that the virus originated in bats and was later transmitted to camels in the distant past (7). The zoonotic transmission is still not fully understood, however, studies on the disease point towards camels as the major reservoir host for the virus and thus the source of infection in humans. Various strains of the virus, which are identical to the human strains, have been isolated from camels in most countries, such as Oman, Qatar, Egypt, and Saudi Arabia.

There is yet no vaccine or specific treatment available at the moment for the disease. Treatment is basically supportive and entirely dependent on the patient's clinical condition at the time of presentation. Standard precautions should be observed by people visiting farms, barns or other places where contact with camels is highly probable. These precautions include regular hand washing before and after touching animals and importantly, avoiding contacts with sick animals (8). Consumption of raw or undercooked meat and milk is a risk factor for zoonotic transmission, therefore, animal products should be processed appropriately through cooking or pasteurization and handled with care to avoid cross-contamination with uncooked food items. Although, camel products have proven to be nutritious, they should only be consumed after cooking or heat treatment or pasteurization (9). Persons who are immunocompromised or have renal failure, diabetes and chronic lung disease are considered to be at high-risk for severe MERS-CoV infection. These groups of individuals should hence avoid contact with camels or consumption of raw camel products (2).

Co-infections of MERS-CoV with other respiratory viruses have been documented in rare cases in the scientific literature $(11,12)$, however, co-infection of other respiratory viruses within themselves is common and has been well documented (13). Also, some studies have reported that co-infection of different variants of MERS-CoV does occur (14), but there is very little data available to date to confirm coinfections of MERS-CoV with other respiratory viruses. This study was therefore conducted to investigate whether coinfection of MERS-CoV 
virus occurs with other respiratory viruses, the objective of which is to determine the prevalence rate of co-infections of MERS-CoV with other respiratory viruses in Saudi Arabia.

\section{Materials and method:}

\section{Study setting and design}

The study was a descriptive crosssectional design conducted in Microbiology Department, King Abdulaziz University, Jeddah, Saudi Arabia, from the period of December 2015 to May 2016.

\section{Subjects and sample collection}

A total of 57 subjects ( 35 males and 22 females) of all age groups positive for MERS COV infection in the outpatient department of five regional laboratories (that perform diagnostic tests only), distributed in different regions of the Kingdom of Saudi Arabia, were enrolled for the study. Ethical approval was obtained from the Scientific Research Ethics Committee of the King Abdulaziz University, Saudi Arabia. Informed consent of each adult subject and assent of children were also obtained.

Nasopharyngeal swab was collected from each subject with flocked swab, which was inserted into the nostril towards the pharynx until resistance was felt. Swab was then rotated three times to obtain samples containing epithelial cells. All swabs were put in virus transport media (VTM) and transported at $-80^{\circ} \mathrm{C}$ to the main Scientific Research Laboratory of King Abdulaziz University, Saudi Arabia, for processing.

\section{Data collection}

All the clinical and laboratory data of subjects were collected via the Health Electronic Surveillance Network (HESN), the national surveillance network for reporting infectious diseases and outbreaks in Saudi Arabia.

\section{Nucleic acid extraction}

Nucleic acid was extracted from $200 \mu \mathrm{l}$ of the nasopharyngeal sample using NucliSens easyMAG system (BioMérieux, USA) following the manufacturer's instructions. The extracted nucleic acid was either amplified immediately or stored at $-80^{\circ} \mathrm{C}$ until needed.

\section{Multiplex RT-PCR with Fast Track Diagnostics Respiratory Pathogen 33}

The extracted nucleic acid was amplified by a one-step multiplex real time PCR using the FTD Respiratory Pathogens (FTD-RP33) assay version 3 which consists of eight-tube multiplex for the detection of respiratory pathogens genes (viruses and bacteria) by TaqMan $\AA$ technology.
Tube 1 multiplex assay was for influenza A (FluA), influenza B (FluB), influenza A (H1N1) swine lineage, and rhinovirus; tube 2 assay was for coronavirus NL63, coronavirus 229E, coronavirus OC43, and coronavirus HKU1; tube 3 assay was for parainfluenza 2, parainfluenza 3, parainfluenza 4, and internal control; tube 4 assay was for parainfluenza 1 , human metapneumovirus A/B, bocavirus, and Mycoplasma pneumoniae; tube 5 assay was for respiratory syncytial viruses $A / B$, adenovirus, enterovirus, and parechovirus; tube 6 assay was for Chlamydia pneumoniae, Streptococcus pneumoniae, Haemophilus influenzae type B, and Staphylococcus aureus; tube 7 assay was for Klebsiella pneumoniae, Legionella pneumophila/Legionella Iongbeachae, Salmonella spp, and Pneumocystis jirovecii; while tube 8 assay was for Moraxella catarrhalis, Bordetella spp (except Bordetella parapertussis), Haemophilus influenzae, and influenza C (FluC).

Five microliters of the template were used for each of the eight multiplex PCR assays. An internal control (BMV), which was included in the FTD kit, was run along each patient sample in the PCR assay. The thermocycling conditions were as follows; $95^{\circ} \mathrm{C}$ for $10 \mathrm{~min}$ and $50^{\circ} \mathrm{C}$ for $15 \mathrm{~min}$, followed by 40 cycles of $95^{\circ} \mathrm{C}$ for $8 \mathrm{~s}$ and $60^{\circ} \mathrm{C}$ for $34 \mathrm{~s}$.

\section{Statistical analysis}

Data were analyzed using SPSS software version 19 (SPSS, Chicago, IL, USA) and the openly available statistical software environment $\mathrm{R}$ version 2.10.1. Comparison of data was done using Fisher Exact test, and $p$ value $<0.05$ was considered significant.

\section{Results:}

\section{Epidemiological statistics}

Of the 57 patients tested (35 males, 22 females), 6 were confirmed positive for one or more respiratory viruses, given a co-infection prevalence rate of $10.5 \%$. The prevalence rate of $14.5 \%(5 / 35)$ in the males was higher (though not significantly) than the rate of $4.5 \%$ $(1 / 22)$ in the females $(\mathrm{OR}=3.500,95 \% \mathrm{CI}=$ $0.3806-32.188, p=0.3889)$. The co-infection rate of $23.8 \%(5 / 21)$ among non-Saudis was significantly higher than $2.8 \%$ rate $(1 / 36)$ among Saudis $(\mathrm{OR}=0.09143,95 \% \mathrm{CI}=0.009855$ $-0.8485, p=0.0217)$. Co-infection of MERS-CoV with other respiratory viruses progressively decreased with age, with prevalence higher in patients below 50 years $(14.7 \%, 5 / 34)$ than patients above 50 years $(4.3 \%, 1 / 23)(\mathrm{OR}=3.79$ $95 \% \mathrm{CI}=0.4928-34.853, p=0.3846)$, with rate being $25 \%(3 / 12)$ in people aged $18-34$ years 
Table 1: Demographic characteristics of MERS-COV patients with co-infection of respiratory viruses

\begin{tabular}{|c|c|c|c|c|c|c|}
\hline $\begin{array}{c}\text { Demographic } \\
\text { characteristics }\end{array}$ & $\begin{array}{c}\text { No of patients } \\
\text { with MERS-CoV } \\
(n=57)\end{array}$ & $\begin{array}{c}\text { No of patients with } \\
\text { co-infection }(\%) \\
(n=6)\end{array}$ & $x^{2}$ & OR & $95 \% \mathrm{CI}$ & $p$ value \\
\hline \multicolumn{7}{|l|}{ Gender } \\
\hline Male & 35 & $5(14.3)$ & - & 3.500 & $0.3806-32.188$ & 0.3889 \\
\hline Female & 22 & $1(4.5)$ & & & & \\
\hline \multicolumn{7}{|l|}{ Age group (years) } \\
\hline $18-34$ & 12 & $3(25.0)$ & 3.649 & - & - & 0.1613 \\
\hline $35-49$ & 22 & $2(9.1)$ & & & & \\
\hline$\geq 50$ & 23 & $1(4.3)$ & & & & \\
\hline \multicolumn{7}{|l|}{ Age group (years) } \\
\hline$<50$ & 34 & $5(14.7)$ & - & 3.793 & $0.4928-34.803$ & 0.3846 \\
\hline$\geq 50$ & 23 & $1(4.3)$ & & & & \\
\hline \multicolumn{7}{|l|}{ Nationality } \\
\hline Saudis & 36 & $1(2.8)$ & - & 0.09143 & $0.009855-0.8482$ & $0.0217 *$ \\
\hline Non-Saudis & 21 & $5(23.8)$ & & & & \\
\hline
\end{tabular}

Table 2: Respiratory viruses identified in patients positive for MERS-COV

\begin{tabular}{lc}
\hline Patient code & Virus detected \\
\hline 3015201185 & HBoV \\
3015201197 & Cor43 \\
3015212494 & HRV, Cor229, FluA, H1N1 \\
3015215102 & HRV \\
3015215107 & RSV \\
3015215113 & HMPV \\
\hline
\end{tabular}

Cor43 =Coronavirus OC43; Cor229 = Coronavirus 229E; FluA = Influenza A; H1N1 = Influenza A swine lineage; RSV = Respiratory Syncytial Virus $A / B ; H M P V=$ Human Metapneumovirus $A / B ; H R V=$ Human rhinovirus; HBoV = Human bocavirus.

Table 3: Demographic statistics of patients co-infected with other viruses indicating each virus

\begin{tabular}{ccccccc}
\hline Viruses & $\begin{array}{c}\text { Number of } \\
\text { patients }\end{array}$ & \multicolumn{2}{c}{ Age group (years) (number and \%) } & \multicolumn{2}{c}{ Gender (number and \%) } \\
\hline Total number & & $18-34$ & $35-49$ & over 50 & Male & Female \\
RSV & 1 & 0 & 0 & $1(100)$ & 0 & $1(100)$ \\
HRV & 2 & $1(50)$ & $1(50)$ & 0 & $1(100)$ & 0 \\
HBoV & 1 & $1(100)$ & 0 & 0 & 0 & $1(100)$ \\
HMPV & 1 & $1(100)$ & 0 & 0 & $1(100)$ & 0 \\
Cor229 & 1 & $1(100)$ & 0 & 0 & $1(100)$ & 0 \\
Cor43 & 1 & 0 & $1(100)$ & 0 & $1(100)$ & 0 \\
FluA & 1 & $1(100)$ & 0 & 0 & $1(100)$ & 0 \\
H1N1 & 1 & $1(100)$ & 0 & 0 & 0 \\
\hline
\end{tabular}

Cor43 =Coronavirus OC43; Cor229 = Coronavirus 229E; FluA = Influenza A; H1N1 = Influenza A swine lineage; RSV = Respiratory Syncytial Virus $\mathrm{A} / \mathrm{B} ; \mathrm{HMPV}=$ Human Metapneumovirus $\mathrm{A} / \mathrm{B} ; \mathrm{HRV}=$ Human rhinovirus; $\mathrm{HBoV}=$ Human bocavirus.

followed by those patients aged between 35-49 years $(9.1 \%, 2 / 22)$ and patients above 50 years $(4.3 \%, 1 / 23)\left(X^{2}=3.649, p=0.1613\right)$ (Table 1$)$. Two of the six patients with co-infection were admitted on suspicion of MERS CoV, based on symptoms while and two were due to contact with the camel. Of those admitted, two died, another one was isolated while the two patients admitted due to contact with camel recovered and were discharged. Of the 6 patients, 4 are from Riyadh city, and 1 each from Jeddah and Kharj. 
Viral prevalence and clinical profiles of patients RT-PCR was utilized in the initial test for MERS-CoV in the entire sample collected. Consistent with the existing circulation pattern and prevalence of MER-CoV in Saudi, 6 samples tested positive for co-infection with other respiratory viruses indicating few nasal carriages of viruses. As illustrated in Table 2, 5 patients were co-infected with a single respiratory virus while 1 patient was co-infected with four respiratory viruses. Human rhinovirus (HRV) was the most prevalent, infecting two of the six patients, while the other viruses infected single patient. In the patient with MERS-CoV, there was co-infection with HRV, Cor229, FluA, and H1N1 (Table 2). The only virus found in a female patient was RSV while the rest were found in the males. The coinfection was more frequent in age group 18-34 years followed by 35-49 years (Table 3 ).

\section{Discussion:}

In the current study of 57 MERS-CoV positive outpatients in these regional laboratories in Saudi Arabia, co-infection prevalence rate of MERS-CoV with other respiratory viruses was $10.5 \%$. This finding is consistent with those of previous studies indicating that coinfection of MERS-CoV with other respiratory viruses has been documented to be low (11, 12). Also, some studies have reported that coinfection of different variants of MERS-CoV do occur (14), however no virus co-infection was detected in individuals below 24 years, showing that prevalence of co-infection of MER-CoV with other viruses is rare in children.

In this study, the frequency of coinfection was higher (though not statistically significant) in the males (14.5\%) than the females $(4.5 \%)$. The higher prevalence in the male could be explained by the lifestyle risk factors such as smoking which could expose them to upper respiratory tract infections. Coinfection was significantly higher $(p=0.0217)$ among the non-Saudis $(23.8 \%)$ than the Saudis $(2.8 \%)$, and our data showed that most of the co-infections were among immigrants from Yemen. Most of the cases $(4 / 6,66.7 \%)$ of co-infections were observed in patients from Riyadh city while one co-infected patient each was from Jeddah and Kharj. This occurrence of MERS-CoV co-infection in Riyadh is higher than a previous study conducted in Riyadh (13), which is not unexpected because, in the earlier Riyadh study, the researchers focused on children less than five years who were inpatient. In contrast, our study focused on outpatients in healthcare centers and of all age groups.
MERS-CoV co-infection occurred more frequently in patients below 50 years (14.7\%) which is consistent with reduced detection of co-infection with increasing age. The MERS$\mathrm{CoV}$ co-infection rate was $25 \%$ in patients aged 18-34 years, followed by those aged 35-49 years $(9.1 \%)$, indicating that increased coinfection of MER-CoV with other viruses was higher among middle-aged people in comparison to children and elderly. It is noteworthy that $33 \%$ of the co-infected patients died, which indicates that co-infection with other viruses is a risk factor for death. This high mortality agrees with the previous report by the Saudi Ministry of Health in 2015 of 458 deaths from a total of 1035 confirmed cases of MERS$\mathrm{CoV}$ with a case fatality rate of $44 \%$.

About $83 \%$ of the co-infected patients were infected with a single respiratory virus while 1 patient $(16.7 \%)$ was co-infected with four respiratory viruses. Of all the viruses, HRV was most frequent co-infector (25\%) affecting 2 of the 6 patients, while all the other viruses had equal frequency of co-infection. One patient was co-infected by four viruses (HRV, Cor22S, FluA and H1N1). The data show the tendency of HRV to co-infect with MER-CoV but also with other viruses. This observation is not easily explained hence there is need for more research on co-infection of HRV with other respiratory viruses. The only virus found in a female patient was RSV but our data indicates that HRV is the most common virus that that co-infect with MER-CoV. The prevalence of co-infection in this study supports previous research of co-infection of MER-CoV with other respiratory viruses.

A major concern of virus co-infection is the tendency for genetic exchange between different viruses through the process of genetic recombination that may result in emergence of more virulent strains of viruses that have increased pathogenicity and enhanced capacity for transmission (15). However, our study was limited by the rather too few numbers of coinfection which is inadequate to support any hypothesis. Nevertheless, our use of advanced molecular diagnostic technique such as the multiplex array aided characterization of the coinfecting respiratory viruses.

\section{Acknowledgments:}

The authors are grateful to Prof. Dr. Aljuhani of the King Abdulaziz University, Saudi Arabia, for his kind supervision, assistance, guidance and encouragement. 


\section{Conflict of interest:}

\section{Authors declared no conflict of interest}

\section{References:}

1. Guery, B., Poissy, J., el Mansouf, L., et al and the MERS-CoV study group. Clinical features and viral diagnosis of two cases of infection with Middle East Respiratory Syndrome Coronavirus: a report of nosocomial transmission. Lancet. 2013: 381: 2265-2272.

2. World Health Organisation (WHO). Middle East Respiratory Syndrome Coronavirus (MERS-CoV). World Health Organization, 2016.

3. Hijawi, B., Abdallat, M., Sayaydeh, A., Alqasrawi, S., Haddadin, A., and Jaarour, N. Novel coronavirus infections in Jordan, April 2012: epidemiological findings from a retrospective investigation. EMHJ. 2013; 19 (suppl 1): S12-S18.

4. World Health Organisation (WHO). Middle East Respiratory Syndrome Coronavirus (MERS-CoV), 2015.

5. Thabet, F., Chehab, M., Bafaqih, H., and Al, M. S. Middle East respiratory syndrome coronavirus in children. Saudi Med J. 2015; 36: 484-486.

6. Zumla, D. S., Hui, S., and Perlman, S. Middle East Respiratory Syndrome. The Lancet. 2015; 386 (9997): 995-1007.

7. Muller, M. A., Meyer, B., Corman, V. M., et al. Presence of Middle East Respiratory Syndrome coronavirus antibodies in Saudi Arabia: a nationwide, cross-sectional, serological study.
Lancet Infect Dis. 2015; 15: 559-564

8. Milne-Price, S., Miazgowicz, K. L., and Munster, V. J. The emergence of the Middle East Respiratory Syndrome Coronavirus. Pathog Dis. 2014; 71: 121-136.

9. Sullivan, K. E., Bassiri, H., Bousfiha, A. A. et al. Emerging Infections and Pertinent Infections Related to Travel for Patients with Primary Immunodeficiencies. J Clin Immunol. 2017; 37: 650-692.

10. Cunha, C. B., and Opal, S. M. Middle East Respiratory Syndrome (MERS), a new zoonotic viral pneumonia. Virulence. 2014; 5: 650-654.

11. Falzarano, D., de Wit, E., Feldmann, F., et al. Infection with MERS-CoV causes lethal pneumonia in the common marmoset. PLoS Pathog. 2014; 10: e1004250.

12. Arabi, Y. M., Arifi, A. A., Balkhy, H. H., et al. Clinical course and outcomes of critically ill patients with Middle East Respiratory Syndrome Coronavirus infection. Ann Intern Med. 2014; 160: 389-397.

13. Abdulhaq, A. A., Basode, V. K., Hashem, A. M., et al. Patterns of human respiratory viruses and lack of MERS-coronavirus in patients with acute upper respiratory tract infections in Southwestern province of Saudi Arabia. Adv Virol. 2017; 2017: 17.

14. Lu, R., Wang, Y., Wang, W., et al. Complete genome sequence of Middle East Respiratory Syndrome coronavirus (MERS-CoV) from the first imported MERS-CoV case in china. Genome Announc 2015;3 (pii): e00818-15.

15. Lai, M. M. Genetic recombination in RNA viruses. Curr Top Microbiol Immunol. 1992; 176: 21-32 